\section{Entre la "integración" y la estigmatización: Construcciones de alteridad en un municipio del noreste argentino}

Between "integration" and stigmatization: Constructions of otherness in a municipality in Northeastern Argentina

\section{Cecilia Benedetti*}

\section{Resumen}

El objetivo de este trabajo consiste en examinar las modalidades de visibilización social de los pueblos originarios en un municipio del Departamento de General San Martín, en el noreste de Salta, Argentina. En el marco de políticas orientadas al reconocimiento de determinados derechos de los pueblos

Doctora en Antropología Social. Investigadora Consejo Nacional de Investigaciones Científicas y Tecnológicas (CONICET) y Universidad de Buenos Aires (UBA), Felipe Vallese $4703^{\mathrm{a}} \mathrm{A}$ Ciudad de Buenos Aires. Correo electrónico: ceci.benedetti1@gmail.com. originarios y la construcción del multiculturalismo en América Latina, mi propósito es abordar cómo se expresan y experimentan estas transformaciones en los contextos locales donde se desarrollan cotidianamente las interacciones interétnicas. Me centraré -por su relevancia en vinculación a este fin- en tres áreas de la administración municipal: la Dirección de Cultura y Turismo, la Coordinación de Deportes y la Secretaría de Desarrollo Humano.

Palabras clave: construcciones identitarias, pueblos originarios, municipio, políticas indigenistas, Departamento de General San Martín.

\begin{abstract}
The aim of this work is to examine the modalities of social visibility of indigenous people in a municipality in General San Martín Department, in northeastern Salta, Argentina. In a frame of politics of recognition of indigenous people's rights and the construction of multiculturalism in Latin American, my purpose is to deal with the ways in which these transformations are expressed and experimented in the context where interethnic relationships take place daily. Because of their importance to this aim, I focus on three municipal areas: the Cultural and Tourism Direction, the Coordination of Sports and the Human Development Secretary.
\end{abstract}

Key words: identity constructions, indigenous peoples, municipality, indigenous policies, General San Martín Department. 


\section{Introducción}

En las últimas décadas, se han desarrollado importantes transformaciones en las políticas indigenistas en América Latina, marcadas por el giro desde las políticas asimilacionistas o de homogenización cultural al reconocimiento de la diversidad cultural en los estados nacionales (Assies 2006, McNeish 2008, Maybury 2003). Bienes y prácticas anteriormente considerados como representaciones de 'atraso' adquieren nuevos significados en el marco de la exaltación de la diversidad, el respeto de las diferencias y el reconocimiento de los derechos culturales (Berrío 2008). ¿Cómo se expresan estos cambios en los contextos locales donde cotidianamente se desarrollan las relaciones interétnicas? Esta pregunta ha guiado la investigación en la que se enmarcan las reflexiones que aquí presento.

El objetivo de este trabajo consiste en considerar las construcciones de alteridad sobre los pueblos originarios en un Municipio del Departamento de General San Martín, en el noreste de Salta, Argentina $^{1}$, que constituye una de las zonas con mayor presencia indígena -wichí, chorote, toba, chané, chiriguano, chulupí, tapietéde la provincia. En dicho departamento, los procesos históricos y actuales que constituyen a los pueblos originarios como un colectivo socialmente diferenciado se han forjado a través de una dinámica particular de relaciones interétnicas, marcada por la dominación económica, política, social y cultural que han sufrido esos grupos (Lagos 2000, Trinchero 2000). Por lo tanto, nos interesa ahondar sobre cómo se expresan dichas políticas de reconocimiento en un contexto donde las

No consignamos el nombre del municipio para mantener el anonimato de las fuentes. relaciones interétnicas se caracterizan por la desigualdad y el conflicto.

El trabajo no se focaliza en comunidades o movimientos indígenas -sin soslayar su importancia- sino en las agencias estatales locales que interactúan con ellos. De este modo, sigo la propuesta de diversos autores (Hale 2002, Martínez 2004, Richards 2010), centrada en considerar -en términos de Hale (2002) - los espacios donde se apunta a dar forma a las subjetividades indígenas, y no tanto en la expresión de estas subjetividades en sí mismas. Nos preguntamos: ¿cómo son interpretadas e implementadas las transformaciones en las políticas indigenistas en el ámbito de las instituciones municipales? ¿A través de qué instancias, mecanismos, líneas de acción se expresan? ¿Cuáles son las construcciones sobre la identidad y cultura indígena que circulan en las instituciones municipales en este contexto?

Me centraré en determinadas áreas de la administración municipal ${ }^{2}$. En primer lugar, considero a la Dirección de Cultura y Turismo (DCT). En esta dependencia me focalizo en las acciones orientadas al fomento del turismo en la zona y el lugar de los pueblos originarios dentro de estos planteamientos ${ }^{3}$. En segundo lugar, contemplo el Torneo Aborigen de Fútbol

\footnotetext{
Cabe mencionar que en el Municipio también se han desarrollado otros programas en el marco de las políticas de reconocimiento que no se han implementado a través de la gestión municipal, sino a través de instituciones de nivel provincial o nacional.

3 En el planteamiento inicial de la investigación, había considerado a los ámbitos culturales como centrales para abordar la construcción de representaciones identitarias sobre los indígenas en el marco de las transformaciones mencionadas. Sin embargo, en el transcurso de la investigación, observamos la necesidad de trascender dicho ámbito, abordando otros espacios relevantes para la construcción de definiciones e imágenes sobre la cultura representativa de los pueblos originarios.
} 
que organiza anualmente la Coordinación de Deportes municipal. Por último, examino las imágenes sobre las culturas indígenas que se reproducen en los discursos vinculados con la implementación de políticas sociales. Desde ya, profundizar exhaustivamente en las dinámicas de estas dependencias trasciende los límites de este trabajo. Aquí me interesa abordarlas como parte de los múltiples espacios donde se construye la visibilidad étnica.

\section{Pueblos originarios y políticas públicas en América Latina}

Los pueblos originarios han adquirido una nueva relevancia en América Latina en las últimas décadas. Ala vezque asistimosa la multiplicación y mayor visibilidad social de los movimientos indígenas (Bartolomé 2003), la temática ha ingresado en las agendas de organismos internacionales y agencias de cooperación, tales como Naciones Unidas (ONU), el Banco Mundial, el Banco Interamericano de Desarrollo (BID), la Unión Europea, la Organización de Estados Americanos (OEA), entre otros. Así, a nivel internacional se han establecido convenios, documentos, programas y proyectos destinados a las poblaciones indígenas, circulando no solamente recursos, sino también definiciones respecto a la cultura y la identidad de los pueblos originarios (Gómez 2002).

En el ámbito de los países latinoamericanos, se han desarrollado cambios en la ideología estatal hacia el multiculturalismo, expresados en políticas orientadas al reconocimiento de un conjunto limitado de derechos indígenas -vinculados con territorios, lenguas, culturas, organización social y política, etc.- aunque sin incidir profundamente en la distribución del poder y los recursos (Hale 2002). Hale, retomando la noción de Roseberry, define al multiculturalismo como la emergencia de un lenguaje contencioso: un marco discursivo común para las negociaciones y demandas, que abre espacios permitidos de reconocimiento cultural y al mismo tiempo la delimita en relación a otros no autorizados (Hale 2014). Por lo tanto, los indígenas se han constituido como un nuevo sujeto de focalización de la política pública (De la Maza 2012). Esto ha implicado el surgimiento de normativas, instituciones, programas y proyectos diferenciados en todos los niveles estatales.

Diversos autores se han abocado al estudio de cómo se expresan estas transformaciones en los ámbitos locales. El foco se ha situado en las agencias estatales locales, élites y otros actores con poder con quienes los pueblos indígenas interactúan cotidianamente, considerando su relevancia para la comprensión de las peculiaridades que adquiere el multiculturalismo en los contextos específicos (Hale 2002, Martinez 2004, Richards 2010). Estos trabajos plantean que dichas políticas no deben ser concebidas como pautas que bajan definidas de una vez y para siempre a la población, y en cambio es necesario contemplar las particularidades que definen su direccionalidad (Richards 2010). Esto no implica señalar la autonomía del nivel local ni relativizar la relevancia del nivel nacional o transnacional, sino marcar la importancia de atender a sus articulaciones (Richards 2010, Hale 2002).

Aquí me centraré en la consideración de las instituciones estatales, poniendo el foco en el ámbito municipal. Me baso en los aportes de los estudios antropológicos sobre el Estado y las políticas públicas para abordar la compleja 
red de instituciones, actores y actividades que dan forma a estas transformaciones. Estos estudios cuestionan las perspectivas centradas en el estado como algo 'dado', y proponen abordarlo como modelo de ordenamiento social que se construye a partir de procesos de lucha y negociación en diferentes niveles y dimensiones (Martínez 2011). Esto implica romper con la visión unitaria del Estado y reconocer la multiplicidad de agencias, organizaciones y agendas a través de las cuales el Estado se construye; así se marca la relevancia de las oficinas locales, en tanto sitios centrales de contacto entre amplios sectores de la población y el estado (Gupta 1995). En esta línea, se propone abordar las múltiples maneras en que las categorías asociadas al universo de la política son conceptualizadas por actores socialmente situados (Balbi y Boivin 2008) y profundizar sobre cómo las políticas son experimentadas y traducidas en el nivel local, en su complejidad, ambigüedad y desorden (Wedel et al. 2005; Shore 2010).

Diversos autores han destacado la relevancia del Estado en la configuración de las identidades sociales. Trouillot define como "efecto de identificación" a la capacidad del Estado de producir "un realineamiento de las subjetividades atomizadas a lo largo de líneas colectivas dentro de las cuales los individuos se reconozcan a sí mismos como iguales a otros" (Trouillot 2001:2). Al mismo tiempo, Corrigan y Sayer (2007) marcan la relevancia del Estado para el establecimiento de las clasificaciones sociales -a través de leyes, instituciones, rutinas y rituales- que consagran determinadas formas y suprimen o marginan otras. Estos aspectos son centrales para la regulación moral, es decir, para la normalización y naturalización de aquello que conforma un conjunto de premisas de una forma particular e histórica del orden social. En la misma línea, Boccara propone realizar una etnografía del estado multicultural, reflexionando sobre las formas locales y diarias de producción de etnicidad por parte del Estado y considerando los "efectos de espacialización, visibilización y etnificación producidos por un conjunto disperso y a veces improvisado de prácticas institucionales" (Boccara 2007: 18)

Las siguientes reflexiones se basan en una investigación en curso comenzada en 2011. El abordaje metodológico de la investigación se estableció desde la Antropología Social, enfatizando en una perspectiva de índole básicamente cualitativa. El trabajo de campo en Salta se desarrolló durante ocho estadías en la zona de entre quince días y un mes de duración. Involucró la observación en instituciones, organismos, comunidades y otros espacios vinculados con la temática de estudio y la realización de 41 entrevistas con funcionarios y agentes que se desempeñan en dichos ámbitos. También mantuve numerosas conversaciones informales con población indígena y no indígena de la zona. Participé en diversos eventos locales, tales como festejos, jornadas, reuniones organizadas por instituciones, etc. Por otra parte, recopilé fuentes diversas: artículos de prensa, folletos, publicidades turísticas, videos institucionales, entre otras. El material registrado fue desgrabado, transcripto, sistematizado y fichado. En tanto la lógica de la investigación se sustentó en la no disyunción entre los procesos de acceso, recolección y construcción de la información con el análisis de la misma (Achilli 2005), la dialectización permanente entre los referentes conceptuales y la información empírica fue central para orientar el proceso de investigación. 


\section{Políticas indigenistas ${ }^{4}$ y pueblos originarios en Argentina}

Históricamente, los pueblos indígenas fueron excluidos de la definición de identidad nacional que proponían los sectores dominantes en Argentina (Juliano 1992, Trinchero 2000). La configuración del Estado nacional ${ }^{5}$ hacia fines del siglo XIX se basó en una "matriz de diversidad fuertemente racializada $y$ profundamente asimétrica" (Briones 2004: 84), que proponía como modelo de identificación positiva los "civilizados", entendiendo como tales "a los europeos, blancos y habitantes de la ciudad" (Juliano 1992: 57). Se asumía que las poblaciones indígenas por su carácter "ignorante y atrasado" constituían un obstáculo para el avance del progreso (Slavsky 1992). Posteriormente, el modelo de identidad nacional se centró en el hombre rural y sus modos de vida, que consideraba a lo indígena como supervivencias de culturas autóctonas.

En este marco, durante buena parte del siglo $X X$, las políticas hacia los pueblos originarios estuvieron débilmente institucionalizadas (Bartolomé 2003). Este panorama comenzaría a transformarse hacia mediados de la década de 1980. Un punto de inflexión fue la reforma de la Constitución Nacional en 1994, que reconoció -entre otros aspectos- la preexistencia étnica y cultural de los pueblos indígenas, a la vez que

Aquí utilizo el término políticas indigenistas para referirme en términos amplios a las actuaciones de las instituciones estatales que involucran a los pueblos originarios.

5 La configuración de Argentina como Estado nación se desarrolló en articulación con su incorporación como exportadora agropecuaria en la división internacional del trabajo. La necesidad de incorporación de territorios a la valorización capitalista implicó el avance estatal sobre las regiones donde hacia el siglo XIX aún vivía población indígena no sometida, desarrollándose una política de exterminio y marginalización sobre estos pueblos (Trinchero 2000). la Ley 23.302 estableció la creación del Instituto Nacional de Asuntos Indígenas (INAI). En Salta, específicamente, la reforma de la constitución provincial reconoció la preexistencia étnica y cultural de los pueblos indígenas de la provincia en 1988. En 2000 se estableció la conformación del Instituto Provincial de los Pueblos Indígenas de Salta (IPPIS), cuyo antecedente fue el Instituto Provincial del Aborigen (IPA), creado en 1986 -dirigido por representantes de las etnias ${ }^{6}$. En 2008 se creó la Subsecretaría de Pueblos Originarios, dependiente del Ministerio de Desarrollo Humano de la provincia. Asimismo, se han sucedido diversos programas y proyectos específicos para pueblos originarios en ámbitos como salud, educación, nutrición, cultura, turismo, con diferentes grados de articulación y relevancia.

El Municipio abordado posee aproximadamente 70.000 habitantes, según datos censales del año 2010. Las actividades económicas más relevantes de la zona son la explotación hidrocarburífera y el cultivo de soja, ambas en manos de capitales transnacionales. Si bien, especialmente en la década de 1990, se produjeron importantes tasas de inversión en estos sectores, la situación socioeconómica de la población presenta altos índices de pobreza y marginalidad (Carenzo 2008). Según el Censo 2010, constituye el municipio con mayor índice de desempleo de la provincia $(10 \%)^{7}$.

La población indígena es de aproximadamente 11.400 habitantes $^{8}$. Al igual que en otras regiones

Cabe aclarar que esta institución funcionó con intermitencias y estuvo intervenida hasta fines de 2008, cuando se estableció su normalización

No se encuentran datos cuantitativos específicos de la zona para ampliar en esta línea.

8 Según datos del Censo realizado en 2001, los datos del Censo 47 
del país, la población indígena constituye uno de los sectores más relegados en cuanto a distribución de los ingresos y acceso a los servicios. Su reproducción económica se asienta sobre diversas fuentes de ingreso, tales como actividades productivas domésticas destinadas tanto al consumo interno como al intercambio en el mercado, trabajo asalariado permanente y temporario, participación en programas provinciales y nacionales de asistencia social. En el municipio existen 47 comunidades con personeríajurídicareconocidas-ya sea provincial o nacional- asentadas tanto en ámbitos rurales como urbanos. Si bien la reforma constitucional de 1994 reconoció la preexistencia étnica de los pueblos indígenas y el derecho a la titularidad de las tierras que habitan ${ }^{9}$, sólo siete de dichas comunidades poseen el título de sus tierras (Buliubasich y González 2009). Esta precaria situación presenta una especial gravedad en este contexto, marcado por la expansión de la frontera agrícola y el crecimiento de la actividad hidrocarburífera, lo cual ha generado diversos conflictos $^{10}$. La Ley 26.160, sancionada en 2006, ha establecido el relevamiento de la situación de las tierras ocupadas por comunidades indígenas (no la entrega) y la suspensión de

La constitución del Estado nación argentino a fines del siglo XIX implicó la necesidad de incorporar las tierras que los indígenas ocupaban a la valorización capitalista. Esto condujo al desarrollo de campañas militares -las más relevantes fueron la Conquista del Desierto en la Patagonia y la Conquista del Chaco en el norte del país, que involucró al territorio que actualmente conforma el Departamento de General San Martín- que implicaron tanto el desalojo de las tierras de dichos pueblos como el despojo de sus medios de trabajo (Trinchero 2000). Los pueblos indígenas conservaron porciones de tierras que formaron parte de sus territorios ancestrales, en muchos casos sin títulos legales, en tierras inscriptas a nombres de particulares o el fisco (Braticevic y Cabana 2014).

10 Un relevamiento sobre conflictos territoriales en Salta señala que de 38 conflictos relevados en la provincia entre 1960 y 2008, 21 corresponden al Departamento de General San Martín. Dentro de este total, 15 casos refieren a comunidades indígenas (Ataide 2010). sentencias y actos procesales que impliquen despojo de dichas tierras. Según un informe del Equipo Nacional de Pastoral Aborigen (ENDEPA) de junio de $2013^{11}$, solo el $12.48 \%$ de las comunidades del país había sido relevado hasta entonces, registrándose en la provincia de Salta el $2.61 \%$ de las comunidades. Cabe aclarar que en el Departamento de General San Martín, en los últimos dos años se ha avanzado significativamente con dicho relevamiento, aunque esto no ha implicado el fin de las expulsiones de los indígenas de las tierras y los conflictos.

Desde el discurso institucional de la gestión municipal actual ${ }^{12}$, las acciones respecto a los indígenas suelen ser promovidas en términos de 'integración', categoría sobre la cual profundizaré a lo largo del trabajo. Como expresión de la retórica multicultural, en los últimos años ha adquirido relevancia la denominación 'pueblos originarios' en los discursos institucionales del municipio para referirse a los indígenas. También se los menciona como 'originarios', tanto en las instancias mencionadas anteriormente como en otras menos preparadas y más espontáneas, como por ejemplo las entrevistas que yo realizo. Mientras que algunos entienden el uso de estas denominaciones como modo de connotar el reconocimiento y respeto de las identidades étnicas, otros simplemente aclaran -en referencia a estas designaciones- "como le dicen ahora". De todos modos, la noción de 'aborígenes', que es la que históricamente se ha utilizado para referirse a estos pueblos, continúa presentando

\footnotetext{
"Nueva advertencia sobre la inejecución de la ley 26160". Disponible en http://endepa.org.ar/contenido/segunda-advertencia-deendepa-sobre-la-ley-26160.pdf.

12 La gestión actual que gobierna el municipio comenzó en 2007 y pertenece a una de las múltiples líneas del Partido Justicialista, afín al gobierno nacional.
} 
vigencia tanto en los discursos oficiales como en los cotidianos.

\section{4. "Mostrar toda la diversidad cultural": Construcciones identitarias étnicas y fomento al turismo}

En la versión oficial de la identidad del Municipio, orientada a la construcción de sentidos de pertenencia en torno a la unidad política, en el "nosotros" en términos de Prats (1997), los indígenas ocupan un lugar relegado. En articulación con las construcciones identitarias nacionales y provinciales predominantes durante la mayor parte del siglo XX, la representación de la cultura local refiere principalmente a lo folklórico, a la vez que presenta una fuerte impronta católica. Si bien las culturas indígenas son definidas como 'lo más autóctono', ello se basa en una concepción en términos de 'otros': supervivencias del pasado excluidas de la narrativa nacional. Así son invisibilizadas en buena parte de las instancias donde se recrean y reproducen sentidos de pertenencia en torno al Municipio. Los monumentos, las placas y los nombres de calles, que rememoran cotidianamente la historia local, refieren a los héroes nacionales y provinciales, a los misioneros franciscanos que se asentaron en la zona, a los fundadores criollos y figuras políticas relevantes; pero ninguno de ellos remite a los pueblos originarios. Por ejemplo, uno de los eventos locales más relevantes donde se expresa simbólicamente la identidad del municipio refiere al desfile que se realiza en el aniversario de la fundación de la ciudad. En el mismo, los indígenas, representados por las autoridades del IPPIS, desfilan junto a las 'colectividades', las que incluye a los sirio-libaneses, bolivianos, griegos, etc. La visibilización junto a las agrupaciones migrantes expresa simbólicamente las barreras para su reconocimiento como parte del 'nosotros'.

En los últimos años, el Municipio comenzó a incentivar incipientemente la actividad turística en la zona. Estas acciones surgieron en articulación con el plan estratégico Salta Sít (Sustentabilidad e integración para crecer) de la Secretaría de Turismo de la provincia de Salta ${ }^{13}$. Si bien el Municipio firmó el convenio para incorporarse en 2009, el fomento al turismo adquirió relevancia hacia 2012, a partir de un cambio en la de gestión en la DCT. En el marco del plan, la zona es denominada 'norte verde' y promocionada a partir de "comunidades indígenas que conservan su cultura original”.

Desde su discurso, este plan recupera los lineamientos de los enfoques centrados en "el patrimonio como recurso" -propulsados por organismos internacionales y agencias de cooperación- que promueven la circulación de producciones, prácticas y saberes étnicos en vinculación con los intereses del turismo y el mercado, concibiendo a la diversidad como "capital económico" (Chaves et al. 2010). Así, se considera que el turismo contribuye al desarrollo local de las comunidades $y$ también al 'fortalecimiento de la identidad', remitiendo a la 'valorización' de prácticas definidas como ancestrales: producciones artesanales, comidas, música y festividades. En cierta medida, estas concepciones retoman el modelo identitario proveniente de las narrativas fundantes de la nación, aunque ahora la identidad étnica se concibe en una diferencia a preservar -más que a modificar- orientada a

El financiamiento de este plan incluye un subsidio del Banco Interamericano de Desarrollo de 35 millones de dólares. 
la mercantilización con fines turísticos. Otro de los aspectos que se destaca desde el discurso provincial es que no se apunta a obligar a las comunidades a que desarrollen el turismo, sino a brindar herramientas para aquellas que quieran incorporarse ${ }^{14}$.

Es interesante señalar que, en el contexto local, el interés por el fomento al turismo trasciende lo económico y forma parte de la construcción de una nueva imagen del Municipio, donde se plantea como una localidad de 'paz social', 'pujante' y 'moderna'. De ese modo, la posibilidad de desarrollar esta actividad indicaría la finalización de la fuerte conflictividad social -que se expresaba centralmente en cortes de ruta denominados "piquetes"15 -en un contexto de altos índices de desempleo y precarización laboral tras la privatización de la empresa estatal Yacimientos Petrolíferos Fiscales (YPF) en la década de $1990^{16}$. Por lo tanto, el fomento al turismo ayuda a consolidar la visibilización pública del Municipio como 'territorio de paz'.

En esta dirección, una de las líneas de acción principales que se señalan desde la secretaría provincial refiere a la creación de un reglamento sobre turismo comunitario, que establece una serie de pautas para aquellas comunidades que quieran encarar la actividad turística.

15 Los piquetes comenzaron a manifestarse en zonas afectas por la desregulación de la actividad hidrocarburífera y la consecuente caída del empleo en la década de 1990, como forma apropiada para demandar la intervención del Estado sobre el problema de la desocupación, "anunciar el conflicto social y producir compromisos del Estado en torno a programas de empleo para personas desocupadas" (Manzano 2013: 46).

16 La actividad petrolera adquirió centralidad en la zona hacia mediados del siglo XX, bajo la gestión de YPF. Esta empresa fue privatizada a partir de la sanción de la nueva Ley de Hidrocarburos de 1992, en el marco de la reforma de ajuste estructural y la implementación de políticas neoliberales en Argentina. Esto implicó una fuerte flexibilización laboral y un alto índice de despidos. Así, el empleo registró una retracción del $75 \%$ en la zona (Svampa y Pereyra 2003).
Para la difusión y sensibilización en relación al turismo en la población local, se han desarrollado varias actividades esporádicas y fragmentadas en articulación entre la DCT y la secretaría provincial, tales como jornadas, capacitaciones y talleres. La responsable de la DCT mencionaba la importancia de la invitación a los indígenas para "empujarlos" de modo que puedan "desarrollarse localmente turísticamente". Sin embargo, en estas instancias ha participado un número limitado de indígenas, que no necesariamente son quienes están interesados en el desarrollo del turismo: en general se trata de militantes, miembros de organizaciones, empleados municipales u otros que, por diversos motivos, han establecido algún tipo de contacto con el Municipio. Al mismo tiempo, acorde al respeto de las pautas culturales, destacaba que no se busca "imponer" que las comunidades reciban a los turistas, sino que participen "solo si ellos quieren". Sin embargo, luego de estos eventos puntuales, no se continuó con otras acciones a largo plazo en las comunidades.

En mis entrevistas, cuando preguntaba a la responsable de la Dirección de Cultura y Turismo cómo se entienden las transformaciones vinculadas con el modelo de la diversidad cultural desde su gestión, ella planteaba la "integración" con otros "iguales": "hacer actividades en forma conjunta", "incluirlos dentro de cada uno de los programas". Sin embargo, en los discursos vinculados al turismo, la noción de diversidad cultural suele ser entendida como diversidad de etnias, enfatizándose los siete pueblos que habitan la zona. Así, en una de las jornadas de sensibilización turística, el Intendente señalaba que el potencial del Municipio para el turismo refería a "mostrar toda la diversidad cultural". Este aspecto se reduce a una cuestión numérica, ya que usualmente los pueblos no son 
diferenciados según sus trayectorias y pautas culturales específicas. Desde la DCT se plantea la "revalorización de la cultura" de los pueblos originarios, aspecto que es comprendido como la preservación de "sus costumbres". Cuando preguntaba a la responsable de la dependencia cómo se implementaba la revalorización, ella mencionaba la invitación a artesanos indígenas a participar en ciertos eventos del Municipio, práctica que no constituye una novedad propia de los últimos tiempos. Asimismo, cabe aclarar que esto se efectiviza esporádicamente ${ }^{17}$. En esta línea, la incorporación de nociones vinculadas con la retórica multicultural se traduce en una nueva denominación de las acciones que históricamente ha desarrollado el Municipio.

A pesar de la gran relevancia que presentan los indígenas en la construcción de una imagen orientada a los visitantes externos, hasta el momento se han impulsado, como atractivos turísticos, un santuario católico ubicado en un paraje del Municipio y una carrera motociclística que se realiza anualmente. Cabe señalar que ambos generan entusiasmo y adhesión, y se instalan como eventos relevantes para los pobladores de la zona. Son intensamente promocionados a nivel local y han recibido subsidios y auspicios por parte de la Secretaría Provincial.

La visibilización de los pueblos originarios se incluye en el marco de estos eventos, como modo de mostrar aquello en "lo que nos diferenciamos del resto de la provincia" para atraer a los turistas. Así, la DCT ha incorporado en su embajada artística -constituida

\footnotetext{
De hecho, hay dos mercados artesanales bajo la órbita de esta dependencia donde, si bien ambos expenden artesanías de los pueblos originarios, sus puestos están ocupados por intermediarios.
}

principalmente por grupos de música folklórica que se presentan en eventos de la zona auspiciados por el municipio- a agrupaciones de pim pim. Las mismas constituyen conjuntos representativos de las comunidades indígenas que participan en los corsos, desfiles que se organizan para los festejos del carnaval. Estas presentaciones recrean ciertos aspectos del arete, una celebración de los pueblos guaraní y chané, que antes de la colonización europea se vinculaba con la maduración del maíz, pero a partir de la acción de los misioneros franciscanos convergió con el carnaval (Rocca y Newbery 1976; Magrassi 1981). Se componen de músicos que ejecutan melodías con flautas e instrumentos de percusión, junto a un conjunto de bailarines que realiza pasos y formas coreográficas características de la celebración. Las mujeres portan coloridos vestidos denominados tipoy; los hombres llevan capas y ponchos y utilizan máscaras de diverso tipo.

Desde el discurso institucional, se señala al pim pim como lo más "autóctono" que distingue a los festejos del Municipio de otros de la región, a la vez que la riqueza histórica y simbólica de esta celebración queda reducida a su categorización como la danza típica o tradicional de los indígenas, siendo concebida como representativa de todas las etnias. En esta línea, también se realizan presentaciones de pim pim en otros eventos, tales como conmemoraciones, actos escolares, encuentros, jornadas, etc. Para los pobladores criollos, el pim pim constituye un ritmo festivo, "algo risueño", tal como lo definió un periodista de la zona.

Es interesante señalar que la DCT invita a las agrupaciones de pim pim a festividades para visitantes externos -por ejemplo los 
festivales que se desarrollan en el marco de la carrera mencionada anteriormente- pero a las actividades orientadas al público local, donde se privilegian los conjuntos folklóricos.

Por lo tanto, mientras que en la reproducción de la identidad local las representaciones culturales de los pueblos originarios tienden a ser marginalizadas, en la construcción de una imagen orientada al turismo -el "nosotros de los otros" (Prats 1997)- las mismas son destacadas como "recurso" de la región. Sin embargo, el lugar relegado de los patrimonios indígenas en la construcción de la identidad local genera dificultades y muestra las contradicciones existentes a la hora de efectivizar acciones en torno a los repertorios patrimoniales indígenas como recurso económico en el marco del fomento al turismo, y de formular cómo se beneficiarán los pueblos indígenas con los ingresos provenientes de esa actividad.

\section{El Torneo de Fútbol Aborigen}

Una de las acciones orientada a pueblos originarios que desarrolla el Municipio, específicamente, refiere a un torneo de fútbol -conocido como Torneo Aborigen y organizado por la Coordinación de Deportes- que comenzó a realizarse hacia fines de la década de 1970. En los noventa, su organización se trasladóal ámbito del IPPIS y este organismo dejó de efectuarlo (la actual gestión municipal promociona como uno de sus logros la reedición del torneo en 2007). En estos últimos años, incrementó la cantidad de participantes -en la actualidad ronda los 1000- incluyéndose al fútbol femenino. En 2014, el Municipio fue sede de un torneo de pueblos originarios organizado por la Secretaría de Deportes provincial.
El Torneo de Fútbol es entendido como una instancia de "integración" de los indígenas, a partir de un deporte concebido como "popular" que comparten todos los sectores sociales. En términos del discurso del Coordinador de Deportes, la integración a través del torneo consiste en que los indígenas puedan "mostrarse", "ser vistos", como modo de "reivindicación por el relegamiento que han sufrido tanto tiempo". De ese modo, en los últimos años se introdujo el lema "Reivindicando los pueblos originarios". Cabe aclarar que desde los discursos municipales se suele considerar "la postergación" de los pueblos originarios, pero más bien desde una postura compasiva que los considera como "desvalidos" e "inferiores". También, la integración se entiende a partir de acciones de "contención social" que trascienden el ámbito deportivo. Por ejemplo, en 2013, se dieron capacitaciones sobre el voto electrónico, a la vez que una de las propuestas aún no concretadas refiere a incluir controles de salud y consultorios móviles.

El torneo está regido por el reglamento de la Asociación de Fútbol Argentino, aunque, informalmente, los empleados de la Coordinación señalan que no todas las reglas se cumplen y diferencian al estilo de juego como de potrero ${ }^{18}$, mientras que el de los criollos se acerca al profesional. Dura aproximadamente dos meses. Previamente, se desarrollan reuniones organizadas por la Coordinación a las que asisten los participantes, y donde se discute el reglamento y otras cuestiones administrativas. De este modo, se destaca que

18 El potrero refiere a terrenos desocupados que espontáneamente ofician de canchas de fútbol. En el sentido común, la expresión fútbol de potrero refiere al estilo de juego que se desarrolla en estos espacios, y es asociado a las clases populares. Suele ser definido como "rústico", en contraposición al fútbol profesional. 
las reglas que lo rigen no se imponen sino que se consensuan "democráticamente" entre la Coordinación y los participantes. El cierre del torneo adquiere gran relevancia, constituyendo el único evento específico de pueblos originarios que se desarrolla en el marco de los festejos del aniversario del Municipio. Incluso, desde hace dos años, la entrega de los premios se realiza en la fiesta nocturna que se celebra en la plaza principal en la víspera al aniversario.

Los premios del torneo ${ }^{19}$ incluyen un trofeo "artesanal" que se traspasa simbólicamente, ya que en realidad permanece en la Coordinación. Representa a un jugador de fútbol tallado en madera oscura y cuyo cabello está pintado de negro, remitiendo a los rasgos físicos estereotipados que caracterizan a los indígenas, cuestión sobre la cual volveremos más adelante. Al mismo tiempo, la factura manual y la decoración con tela de chaguar wichí aluden a producciones artesanales, que constituyen referentes patrimoniales centrales en la visibilización de los pueblos originarios.

La acreditación de la adscripción étnica de los participantes es uno de los aspectos que causa mayores controversias en el torneo, y que prácticamente ocupa todo el tiempo de las reuniones preparatorias. La representación de los equipos refiere a las comunidades indígenas ${ }^{20}$; por lo tanto, la pertenencia a las mismas constituye un requisito central en esta línea. Sin embargo, en tanto las comunidades son concebidas más como unidades territoriales que como formas organizativas, esta cuestión suele presentar ambigüedades, ya que en

\footnotetext{
19 Los otros premios consisten en carne para asado, fardos de gaseosa, camisetas, pelotas, trofeos y medallas.

20 Anteriormente, los equipos representaban a las etnias.
}

estos espacios residen también sujetos que adscriben como criollos. Así, algunos equipos comenzaron a incluir criollos -en general debido a las cualidades deportivas personales- en sus listas para participar en el torneo, haciéndolos pasar por indígenas.

Debido a las constantes quejas entre equipos, el coordinador solicitó al IPPIS un listado con los integrantes de todas las comunidades para dirimir esta cuestión. En respuesta, el IPPIS explicitó que podían ser considerados indígenas quienes tuvieran madre o padre perteneciente a alguna etnia y que eligieran reivindicarse como tal, desplazando el criterio de la residencia por el de la consanguineidad y la autoadscripción. Sin embargo, esto también planteó conflictos respecto a cuál era el parentesco válido, ya que algunos proponían considerar no solo a los padres sino también a otros parientes directos. Finalmente, se consensuó como requisito el documento de identidad que demostrara la residencia en la comunidad; mientras que quienes, por diversos motivos, presentaran algún certificado diferente, deberían adjuntar una nota de aval del cacique. Sin embargo, desde la Coordinación se quejan, porque a veces el cacique "firma" acreditando que son indígenas, cuando en realidad no es así, y ellos "no pueden hacer nada".

A pesar de estas discusiones, quienes se desempeñan en la Coordinación señalan que "todos saben quiénes son indígenas", aludiendo a los rasgos físicos como aquello que permite "verdaderamente" reconocerlos. En esta línea, en una entrevista el Coordinador mostraba las venas de su brazo -en referencia a la sangrepara explicar dónde reside la condición étnica. Si bien esto no se expresaba públicamente en las reuniones, cuando los participantes consultaban 
porfuera delas mismas, las empleadas señalaban que -más allá de los requisitos formales- ellas "se dan cuenta", ya que "si viene un rubio de ojos celestes se sabe que no es un aborigen". Por lo tanto, las construcciones racializadas ${ }^{21}$ respecto a la diferencia étnica son invocadas como válidas en oposición a otros criterios que son considerados menos "efectivos" para el reconocimiento de los indígenas. Es interesante señalar que los aspectos biológicos también están presentes en los nuevos criterios del IPPIS para la definición de la etnicidad, aunque la apelación a la sangre no se expresa a partir de la apariencia corporal externa, sino en términos de relaciones de consanguineidad.

Por otra parte, para solucionar estos conflictos, en los últimos años se ha establecido un cupo de criollos para cada equipo. En un principio, el Coordinador consideró positivo este aspecto para favorecer la "integración". Sin embargo, implicó nuevas discusiones. Mientras que algunos sostienen la posibilidad de ampliar la cantidad de criollos permitida -aduciendo que no juntan suficientes jugadores indígenas para formar los equipos- otros apuntan a reducir o incluso excluir a los criollos del torneo, señalando que el torneo pierde su carácter indígena.
A través del torneo se condensan -con distinto grado de relevancia- diversas formas de visibilidad de la alteridad étnica. Por un lado, se expresan aquellas construcciones que históricamente se han constituido como marcadores de la diferencia indígena, especialmente los rasgos físicos externos. Por otro lado, si bien la realización del torneo de fútbol no constituye una novedad, ha incluido algunos aspectos vinculados con las nuevas formas de visibilización de los indígenas en el marco del multiculturalismo. Así se incorpora la noción de reivindicación y la participación en la actividad incluye nuevas formas de definición de la identidad étnica, aunque adecuadas a la lógica de la administración estatal, expresándose en certificados, listados, etc. Unas y otras construcciones de alteridad generan ambigüedades. Incluso los rasgos físicos, que se presentan como los aspectos concebidos como definitorios de lo étnico, no son precisos, y muchas veces son compartidos con los criollos ${ }^{22}$. Sin embargo, mientras que estos presentan efecto de verdad, los nuevos criterios adquieren legitimidad más bien en términos de respeto a las pautas culturales, que por ser considerados como marcadores auténticos de la diferencia étnica.

\section{Pueblos originarios y políticas sociales}

\section{Si bien a través de la Secretaría de Desarrollo} Humano municipal prácticamente no se implementan programas sociales diferenciados para indígenas ${ }^{23}$, estos pueblos constituyen en la noción de racialización propuesta por Arias y Restrepo, quienes la definen como un "proceso de marcación-constitución de diferencias en jerarquía de poblaciones a partir de diacríticos biologizados que apelan al discurso experto, e independientemente que su inscripción sea en el cuerpo-marcado o en el sujeto moral, pero siempre apuntando a la gubermentalización de la existencia de las poblaciones así racializadas" (Arias y Restrepo, 2010: 58). Entre uno de los aspectos centrales del concepto de raza, los autores destacan la "valoración de la constitución física, desde su apariencia externa, como marcador o su composición interna como vehículo y determinante en la constitución socio-moral" (Arias y Restrepo 2010: 59).
22 Esta cuestión es señalada por Escolar en relación a las identificaciones huarpes (Escolar 2007).

23 La única acción específica para indígenas que involucra a la Secretaría refiere al apoyo logístico -transporte y personal- para la distribución de bolsones alimentarios en las comunidades, otorgados por la Secretaría de Pueblos Originarios Provincial. 
una porción importante de los destinatarios de las acciones de la misma. Según la estimación del actual secretario ${ }^{24}$, los pueblos indígenas constituyen el $60 \%$ de los beneficiarios. En esta línea, la Secretaría suele ser valorada como un espacio estratégico de acceso a los recursos de la asistencia social por estos pueblos. Por ejemplo, es la única dependencia municipal donde ocasionalmente interceden las autoridades del IPPIS.

Informalmente, se considera que el área de atención de los indígenas en la Secretaría refiere a los programas focalizados ${ }^{25}$, aunque los mismos incluyen a toda la población local. Los más relevantes consisten en la entrega de tarjetas para la adquisición de alimentos y están orientados a cubrir riesgos nutricionales, ya sea para niños o familias. Otra de las áreas con gran preeminencia para pueblos originarios remite a las pensiones destinadas a personas en condiciones definidas como en situación de 'vulnerabilidad social': madres de siete hijos o más, mayores de 70 años o personas con incapacidades para desempeñarse laboralmente. Por fuera de estos programas, la Secretaría realiza entrega de diversos tipos de ayuda frente a demandas puntuales: bolsones alimentarios, materiales para la construcción, colchones, medicamentos, viáticos por problemas de salud, medicamentos, etc.

Cabe señalar que nuestro trabajo de campo en esta dependencia se realizó principalmente entre 2011 y 2013. A fines de 2013, hubo un cambio de autoridades en la Secretaría, acompañado de una mudanza de oficinas. A menos que sea aclarado, en este trabajo me refiero a las autoridades anteriores y no a las actuales.

25 Así, la primera vez que concurrí a la Secretaría me orientaron hacia el sector de programas focalizados, a la vez que, cuando preguntaba cuáles eran las acciones específicas para indígenas, me mencionaban estos programas.
Las construcciones respecto a la diferencia étnica son centrales en la implementación y evaluación de las acciones respecto a los pueblos originarios. En esta línea, los empleados de esta dependencia se destacan a sí mismos como quienes conocen "verdaderamente" a los indígenas. Esto refiere centralmente a romper con la idea predominante en los imaginarios sociales de la zona respecto a que estos pueblos "son pobrecitos"; sujetos que, debido a sus condiciones "inferiores", necesitan de la caridad y la asistencia social.

Así, quienes se desempeñan en la Secretaría suelen destacar que los indígenas "son los que más reciben", en referencia a las ayudas sociales. Sin embargo, explican que estas ayudas no logran el mejoramiento de las condiciones de vida de estos pueblos debido a "su cultura". Los aspectos definidos como diferencias culturales son heterogéneos, aunque comparten estar anclados en criterios de ancestralidad e imposibilidad de cambio. Por ejemplo, el anterior Secretario de esta dependencia señalaba: "Muchas veces uno les ha hecho una vivienda y ellos no (...) Viven su cultura. Ellos piden, quieren, pero una vez que sale, parecería ser como que no se adaptan, ahí nomás vuelven a vivir a su tierra, y siguen al lado de la casa, la utilizan como cocina" (Entrevista, junio de 2013). Sin embargo, el punto central para explicar la escasa efectividad de las ayudas sociales refiere a su "incapacidad" para administrar correctamente los recursos que reciben. De esa forma, se señala que "tienen otras prioridades", "se gastan todo en electrodomésticos", y venden los recursos de primera necesidad para comprar "cosas superfluas". Tal como señalé, estos aspectos son concebidos como milenarios y, por lo tanto, inmutables. Incluso se destaca que los indígenas son 'cerrados', para 
justificar la imposibilidad de un mejoramiento en sus condiciones de vida. Estos aspectos, concebidos como diferencia étnica, constituyen prejuicios extendidos a los sectores subalternos, a través de los que se les responsabiliza por las desiguales condiciones económicas en las que viven. De este modo, las desigualdades sociales son construidas como diferencias culturales.

Al mismo tiempo, se considera que los recursos de la asistencia social han implicado la pérdida de las prácticas étnicas. Así, se señala que los indígenas ya no realizan sus actividades 'tradicionales' destinadas a la subsistencia y, en cambio, se acostumbraron a vivir de los planes sociales. Por ejemplo, se destaca la disminución de la producción artesanal, sin tener en cuenta las escasas ganancias económicas que, en la mayoría de los casos, implica esta actividad.

Es importante destacar que estas construcciones no son exclusivas de quienes se desempeñan en estas instituciones $y$, en cambio, constituyen modos de calificación estigmatizados ampliamente difundidos en la zona. La fuerte discriminación social hacia estos pueblos se manifiesta cotidianamente en diversos discursos y prácticas. Tal como señala Prinzio (2002), los indígenas son considerados como "vagos, improductivos, sucios, desposeídos, adjudicándosele todos los males posibles porque son diferentes" ${ }^{26}$. Sin embargo, adquieren legitimidad en tanto se presentan como "saber" adquirido en el accionar institucional.

Por otra parte, la visibilidad del indígena como sujeto destinatario de políticas diferenciadas

26 Yo analicé los procesos de estigmatización en torno a la producción artesanal en Benedetti (2012). ha implicado la etnicización de las disputas por los recursos de la asistencia social. Así, según los funcionarios de la Secretaría, los criollos "piden más", ya que "están viendo que a los hermanos aborígenes les damos"; reclaman que "conviene ser aborigen para recibir cosas". Cabe aclarar que los programas, becas y ayudas para indígenas se implementan, principalmente, a través de instituciones específicas -como el IPPIS, INAI, etc. Sin embargo, estas cuestiones también se expresan en esta oficina municipal.

Otro de los aspectos que constituye una de las temáticas centrales planteadas entre los empleados de la Secretaría respecto a los indígenas, remite al aumento de sus demandas y movilizaciones en el último tiempo. En menor medida, algunos consideran como un cambio positivo que estos pueblos "ya no se esconden" y "hacen valer sus derechos". Otros, desde una perspectiva reprobatoria, consideran que ahora los indígenas no "se conforman" con recibir "cosas básicas" y "piden más"; además, cuando no consiguen lo demandado "se ponen revoltosos", "piden con prepotencia", "tiran la bronca para conseguir". En general, estos modos de pedir son habituales en la Secretaría, y así no es excepcional en este ámbito escuchar discusiones y amenazas de cortes y manifestaciones. Usualmente, estas modalidades son atribuidas a los piqueteros, en vinculación a las protestas mencionadas anteriormente. En gran medida, los piqueteros están estigmatizados en el contexto local: se considera que apelan a estos modos porque "quieren recibir todo de arriba" (en referencia a los planes sociales) y "no trabajar".

Así, cuando los indígenas recurren a estas modalidades -tales como los cortes de ruta- se entiende que adoptaron "las peores costumbres 
de los criollos", y el aumento de las demandas de los pueblos originarios es concebido como "pérdida de la identidad". Es posible asociar estos aspectos con ciertas imágenes que atraviesan los modos de visibilidad de los indígenas, que los definen como "dóciles" y "sumisos". Por lo tanto, estas características -consideradas como "étnicas"- quedarían diluidas en el reclamo por sus derechos. Por otra parte, es interesante destacar que, en la mayoría de los casos, los cortes de ruta de los indígenas no están orientados a la Secretaría -por ejemplo, en los últimos meses la mayoría se relacionaba con un conflicto por la ejecución de un plan de viviendas del IPPIS. Sin embargo, las demandas por los recursos por parte de los indígenas se visibilizan de este modo, y no en términos individuales como suele ocurrir en la Secretaría.

La nueva relevancia de los pueblos originarios como sujetos de políticas públicas, ha implicado una nueva visibilidad de los mismos en el ámbito de las políticas sociales a nivel municipal, aunque no tanto acciones dirigidas específicamente a ellos. Los modos de calificación que circulan en esta dependencia los deslegitiman como beneficiarios de dichos recursos. Por un lado, se apela a la "ancestralidad", pero concebida en términos de atraso, para justificar la escasa efectividad de las políticas sociales en la transformación de las condiciones sociales de los pueblos originarios. Por otro lado, se invocan aspectos que, si bien son presentados como diferencias culturales, remiten en mayor medida a las condiciones de subalternidad de estos pueblos. Al mismo tiempo, sus reclamos son desacreditados, considerando que las protestas implican la "pérdida de la identidad indígena" y la asimilación a la figura del "piquetero", cuyos reclamos no son concebidos como válidos en el contexto local.

\section{A modo de cierre}

El objetivo de este trabajo consistió en analizar las construcciones de alteridad étnica en uno de los municipios con mayor población indígena del norte de Argentina, en el marco de las transformaciones en las políticas indigenistas acontecidas en las últimas décadas. Me interesó conocer cómo se expresan, implementan y traducen estos cambios a nivel local, considerando que constituyen los espacios donde se experimentan cotidianamente las relaciones interétnicas. Con este fin, indagué en tres áreas de la administración municipal que desarrollan acciones que involucran a los pueblos originarios y sus construcciones identitarias. En la línea ofrecida por las propuestas de etnografía del Estado multicultural, apunté a comprender la construcción de la etnicidad a partir de una visión desagregada del Estado, contemplando sus múltiples espacios y prácticas. Abordando los discursos multiculturales como instancias de definición legítima de lo étnico, me interesó comprender a través de qué modalidades los mismos se articulan en la dinámica de las dependencias municipales.

Las transformaciones en el campo de lo étnico no han implicado en gran medida la existencia de programas específicos para la población indígena, centrados en las instituciones municipales. En cambio, han involucrado la incorporación de nuevas nociones y prácticas en las acciones que el Municipio ya desarrollaba, implementándose modalidades heterogéneas en las diversas oficinas locales.

En articulación con el Plan Turístico Provincial, la visibilización de lo étnico se propone en términos de la oferta de "diversidad 
cultural" que el Municipio puede ofrecer para diferenciarse de otras propuestas turísticas. Desde la gestión de la DCT, dicha diversidad se objetiviza en determinadas prácticas definidas como representativas de lo indígena en general y caracterizadas en términos de ancestralidad, que se articulan con las nociones prevalecientes respecto a los pueblos indígenas en tanto "otros" a los que hay que integrar con la población criolla, más que a favor del reconocimiento de la diversidad de la identidad local. La incorporación de los indígenas en las actividades y eventos vinculados al turismo se produce más para denotar la versión de la identidad regional propuesta por la secretaría provincial, que para la efectiva inclusión de dichos pueblos en esta actividad.

En el caso del Torneo de Fútbol, la retórica multicultural se incorpora a una acción que históricamente ha desarrollado el Municipio, hecho que ahora se plantea como una "reivindicación" de los pueblos originarios frente a su "postergación", aspecto central en las formas de visibilidad de los indígenas que circulan en el contexto local. Para la definición de los participantes del torneo, se apela a nuevos criterios, como la autoadscripción y pertenencia a la comunidad, y se considera la autoridad de las instituciones indígenas en esta línea, aunque adecuados a los marcos administrativos. A la vez que estos criterios son aceptados como "democráticos" en su definición, son deslegitimados como endebles e imprecisos en la práctica, apelando a las antiguas definiciones -en términos racialescomo aquellas que presentan validez. Por otra parte, la nueva visibilidad de los pueblos originarios permitió que la acción trascendiera el espacio local, y que se articule con propuestas del ámbito provincial.
En vinculación con las políticas sociales, la diferencia cultural no opera para definir una línea de acción orientada a pueblos originarios, sino para diferenciar a los pueblos originarios como destinatarios de las mismas. De este modo, determinados aspectos ligados a las condiciones de subalternidad de los indígenas son construidos en términos de "elementos culturales", para explicar la escasa efectividad de dichas políticas en estas poblaciones. Si bien estas explicaciones no constituyen una novedad, adquieren una nueva legitimidad en términos de los discursos multiculturales. De este modo, la construcción de la visibilidad de los pueblos originarios centrada en prácticas consideradas "ancestrales", se constituye como argumento para explicar su condición de "postergados". Al mismo tiempo, la politización de los indígenas es concebida en términos de "pérdida identitaria", delimitando los espacios que quedan fuera del reconocimiento del discurso multicultural en términos de Hale.

La incorporación de la retórica multicultural funciona como instancia de legitimación en diversas líneas, ya sea como un modo correcto de abordar aquellas acciones que incluyen la visibilización de los pueblos originarios, como forma de reivindicación, o para explicar a las políticas que los incluyen como destinatarios. Esta legitimación opera más hacia "afuera" -los turistas, las instituciones provinciales, la antropóloga de Buenos Aires- que en la construcción de nuevas imágenes orientadas a la población local, donde presentan validez las construcciones marcadas por la discriminación y el prejuicio.

Los discursos que circulan a nivel transnacional y nacional en torno a lo étnico produjeron un consenso respecto al respeto y reconocimiento 
de las diferencias culturales, pero el contenido de las diferencias étnicas y su direccionalidad en las acciones específicas se define y negocia en las relaciones entre los agentes de los diferentes niveles por donde dichos discursos circulan. De este modo, podemos pensar los modos de visibilidad sobre lo étnico que se configuran en las instituciones municipales en términos de la intersección entre la búsqueda de legitimación a partir de la definición social legítima sobre lo étnico que circula en las esferas transnacionales y nacionales, por un lado, y aquellas representaciones producto de la especificidad de la dinámica interétnica -históricamente conflictiva- a nivel local, por otro.

\section{Bibliografía}

Achilli, Elena. 2005. Investigar en antropología social. Los desafíos de transmitir un oficio. Rosario: Laborde Editor.

Arias, J. y Restrepo, E. 2010. "Historizando raza: propuestas conceptuales y metodológicas". C y E 3. Disponible en: http://www. ram-wan.net/restrepo/documentos/historizando\%20raza.pdf.

Assies, W. 2006. Reforma estatal y multiculturalismo latinoamericano al inicio del siglo XXI. Disponible en: http:// chakana.nl/files/pub/Assies_2003_reforma_estatal.pdf (visitado el 12 de noviembre de 2014).

Ataide, S. 2010. Políticas de planificación regional y de desarrollo territorial rural y conflictos territoriales concomitantes. Estudio de caso en la provincia de Salta (1960-2008). Tesis de Licenciatura en Geografía, Facultad de Filosofía y Letras, Universidad de Buenos Aires.

Balbi, F. y Boivin, M. 2008. "La perspectiva etnográfica en los estudios sobre política, estado y gobierno". Cuadernos de Antropología Social 27: 7-17.

Bartolomé, M. 2003. "Movimientos indios y fronteras en América Latina". Identidade, fragmentacao e diversidade na América Latina. Scout, P. y Zarur, G. (Orgs.). Recife: Editorial Universitaria da UFPE. 49-86.

Benedetti, C. 2012. "Diferencias y desigualdades: reflexiones sobre identidad étnica y producción artesanal chané destinada a la comercialización". Revista Alteridades 43: 21-33.

Berrío, L. 2008. "La diversidad cultural: de conflicto a patrimonio de la humanidad. Miradas sobre el multiculturalismo en América Latina". Estudios latinoamericanos 22. Disponible en: http://www.journals.unam.mx/index.php/rel/article/view/20266 (visitado el 12 de noviembre de 2014).

Boccara, G. 2007. "Etnogubermentabilidad. La formación del campo de la salud en Chile". Chungara 39: 185-207.

Braticevic, S. y Cabana, J. 2014. "Aplicación de políticas públicas orientadas a pueblos indígenas. Un análisis comparativo del avance de la frontera agraria y sus contradicciones con el Programa de Relevamiento de la Ley 26.160". Estado y Políticas Públicas 2: 187-204.
Briones, C. 2004. "Construcciones de aboriginalidad en Argentina". Société suisse des Américanistes 68: 73-90.

Buliubasich, C. y González, A. 2009. Los pueblos indígenas de la Provincia de Salta. La posesión y el dominio de sus tierras, Departamento de General San Martín. Salta: Centro Promocional de las Investigaciones en Historia y Antropología.

Carenzo, S. 2008. Un universo de objetos en circulación: procesos de valorización y transformaciones en las economías domésticas chané de Campo Durán. Tesis doctoral de la Facultad de Filosofía y Letras, Universidad de Buenos Aires.

Chaves, M., Montenegro, M. y Zambrano, M. 2010. "Mercado, consumo y patrimonialización cultural". Revista Colombiana de Antropología 46: 7-26.

Corrigan, P. y Sayer, D. 2007. "El gran arco. La formación del estado inglés como revolución cultural”. Cuaderno de Futuro 23: 39-116.

De la Maza, F. 2012. "La noción de indígena en las prácticas estatales locales. El caso de tres comunas de la Araucaria, Chile". Cuadernos de Antropología Social 36: 91-117.

Escolar, D. 2007. Los dones étnicos de la Nación. Identidades huarpes y modos de producción de soberanía en Argentina. Buenos Aires: Prometeo.

Gómez, A. 2002. "Estructura de Oportunidad Política de los movimientos indígenas Latinoamericanos". Alteridades 23: 109123.

Gupta, A. 1995. "Blurred boundaries: the discourse of corruption, the culture of politics, and the imaginated state". American Ethnologist 22 (2): 375-402.

Hale, Ch. 2014. "Entre lo decolonial y la formación racial: luchas afro-indígenas por el territorio y por (¿o en contra de?) un nuevo lenguaje contencioso". Cuadernos de Antropología Social, 40: 9-37.

2002. "Does the multiculturalism menace? Governance, cultural rights and the politics of identity in Guatemala". Journal of Latin American Studies 34 (3): 485-524. Juliano, D. 1992. "Estrategias de elaboración de identidad". 
Etnicidad e identidad. Hidalgo, C. y Tamagno, L. (Comps.) Buenos Aires: Centro Editor de América Latina. 50-63.

Lagos, M. 2000. La cuestión indígena en el Estado y en la sociedad nacional. Gran Chaco, 1870-1920. San Salvador de Jujuy: Universidad Nacional de Jujuy.

Magrassi, G. 1981. Chiriguano-Chané. Buenos Aires: Ediciones Búsqueda y Centro de Artesanía Aborigen Yuchan.

Manzano, V. 2013. La política en movimiento. Movilizaciones colectivas y políticas estatales en la vida del Gran Buenos Aires. Rosario: Prohistoria.

Martínez, S. 2011. "Revisitando al Estado: límites y posibilidades de las aproximaciones contemporáneas al estudio del ordenamiento estatal". Actas del X Congreso Nacional de Sociología. Cali, del 2 al 4 de noviembre de 2011.

Martínez, C. 2004. "We are against the goverment although we are the goverment. State institutions and indigenous migrants in Baja California in the 1990s". The Journal of Latin American Anthropology 9 (2): 352-381.

Maybury, D. 2003. "Identidade etnica em estados pluriculturais". Identidade, fragmentacao e diversidade na América Latina. Scout, P. y Zarur, G. (Orgs.). Recife: Editorial Universitaria da UFPE. 11-25.

McNeish, J. 2008. "Beyond the permitted indian? Bolivia and Guatemala in an era of neoliberal developmentalism". Latinamerican and Caribbean Ethnic Studies 3 (1): 33-59.

Prats, L. 1997. Antropología y patrimonio. Barcelona, Ariel.

Prinzio, G. 2002. Categorías identitarias en la frontera argentino-boliviana. Tesis de licenciatura en Antropología, Facultad de Humanidades, Universidad Nacional de Salta, Salta.

Richards, P. 2010. De indios y terroristas: como el estado y las elites locales construyen el sujeto mapuche. Disponible en: http:// www.observatorio.cl/sites/default/files/biblioteca/traduccion_ final_patricia_richards_multiculturalismo_neoliberal_y_elites_ locales.pdf (visitado el 12 de noviembre de 2014).

Rocca, M. y Sara N. 1976. "El carnaval chiriguano chané". Cuadernos del Instituto Nacional de Antropología 8: 43-91.

Shore, C. 2010. "La antropología y el estudio de la política pública: reflexiones sobre la formulación de las políticas". Antípoda 10: 21-49.

Slavsky, L. 1992. "Etnodesarrollo". Etnicidad e identidad. Hidalgo, C. y Tamagno, L. (Comps.) Buenos Aires: Centro Editor de América Latina. 168-192.

Svampa, M. y Pereyra, S. 2003. Entre la ruta y el barrio. La experiencia de las organizaciones piqueteras. Buenos Aires: Biblos.

Trinchero, H. 2000. Los dominios del demonio. Buenos Aires: EUDEBA

Trouillot, M. 2001. "The anthropology of the state in the age of globalization: close encounters of the deceptive kind". Current Anthropology 42 (1): 125-138. Traducción de Alicia Comas, Cecilia Varela y Cecilia Diez.

Wedel, J., Shore, C., Feldman, G. y Lathrop, S. 2005. "Towards an anthropology of public policy". The Annals of the American Academy of Political and Social Science. 600. 30-51. 